\title{
Differences in Characteristics/Complaints and Referral of Attention-Deficit/Hyperactivity Disorder Patients with and without Depression: Focus on Korean Children and Adolescents
}

\author{
Won-Seok Choi, MD ${ }^{1}$, Hyun Ju Hong, MD, PhD ${ }^{1}$, Myung Hun Jung, MD, PhD ${ }^{1}$, Narei Hong, MD, PhD ${ }^{1}$, \\ Yong-Sil Kweon, $\mathrm{MD}, \mathrm{PhD}^{2}$, Geon Ho Bahn, $\mathrm{MD}, \mathrm{PhD}^{3}$, Ki-Hwan Yook, MD, PhD, \\ Dong-Won Shin, MD, $\mathrm{PhD}^{5}$, Duk-In Jon, $\mathrm{MD}, \mathrm{PhD}^{1}$ \\ ${ }^{1}$ Department of Psychiatry, Hallym University Sacred Heart Hospital, Anyang, ${ }^{2}$ Department of Psychiatry, College of Medicine, The Catholic \\ University of Korea, Seoul, ${ }^{3}$ Department of Psychiatry, Kyung Hee University School of Medicine, Seoul, ${ }^{4}$ Department of Psychiatry, CHA \\ Bundang Medical Center, CHA University, Seongnam, ${ }^{5}$ Department of Psychiatry, Kangbuk Samsung Hospital, Sungkyunkwan University \\ School of Medicine, Seoul, Korea
}

Background: Children and adolescents with attention-deficit/hyperactivity disorder (ADHD) and depression present with different clinical characteristics compared to those without other psychiatric comorbidities (i.e., ADHD alone). This study aimed to determine the differences in clinical characteristics, complaints, and referral routes between patients with ADHD with and without depression.

Methods: The study included 1,231 children and adolescents in Korea. The demographic characteristics, referral routes, and chief complaints were identified and analyzed using the subjects' electronic medical records of their first outpatient visit.

Results: The mean age and proportion of female subjects with depression and ADHD (ADHD-D, $n=120$ ) were significantly higher than those of patients with ADHD alone (ADHD-0, $n=1,111)$. Furthermore, referral requests by the caregiver $(p=0.037)$ and patient $(p=0.006)$ were significantly higher in the ADHD-D group. In contrast, referrals via schools $(p=0.009)$ and other medical institutions $(p<0.001)$ were significantly higher in the ADHD-0 group. There were more complaints of depression, anxiety, mood dysregulation, suicidal ideation, and self-harm behaviors among the patients in the ADHD-D group. However, complaints of inattention were more common among the patients in the ADHD-O group compared to those in the ADHD-D group ( $p<0.001)$.

Conclusion: This study revealed several differences in the demographic characteristics, referral routes, and chief complaints of the patients and caregivers between patients with ADHD with and without coexisting depression. Further investigations using structured psychiatric diagnostic tools are warranted.

Keywords Attention deficit-hyperactivity disorder; Depression; Adolescent; Hospital referral

\section{INTRODUCTION}

Attention-deficit/hyperactivity disorder (ADHD) is a neurodevelopmental disorder characterized by attention deficit, impulsiveness, and hyperactivity, and is one of the most prevalent pediatric psychiatric disorders, causing impairments in many core functions such as learning and social skills [1]. It is well known that children and adolescents with ADHD have more than two comorbid psychiatric disorders [2,3]. The common psychiatric

Received June 11, 2020, Revised June 25, 2020, Accepted June 25, 2020

Correspondence: Duk-In Jon, MD, PhD

Department of Psychiatry Hallym University Sacred Heart Hospital, 22 Gwanpyeong-ro 170beon-gil, Dongan-gu, Anyang 14068, Korea

TEL +82-31-380-3750 FAX +82-31-381-3753 E-mail cogni@naver.com ORCID https://orcid.org/0000-0002-1565-7940

Copyright $@$ by Korean Society for Affective Disorders. All Rights reserved.

This is an Open Access article distributed under the terms of the Creative Commons Attribution Non-Commercial License (http://creativecommons.org/licenses/ by-nc/4.0/) which permits unrestricted non-commercial use, distribution, and reproduction in any medium, provided the original work is properly cited. 
comorbidities include conduct disorder, oppositional defiant disorder [4], anxiety disorder, and mood disorder $[5,6]$. The rate of major depressive disorders in children and adolescents with ADHD is $2 \%$ to $9 \%$ [7]. Symptoms of depression, such as diminished concentration, loss of interest, and psychomotor retardation, cause deterioration of social and academic functioning in adolescents with ADHD.

ADHD patients with depression present a higher risk of suicidality, poor prognosis [8], impulsiveness, and hyperactivity [9]. Furthermore, these patients demonstrate more anxiety, aggressive behavior, somatic symptoms [10], externalization disorder, social withdrawal, and psychomotor retardation [11] compared with those without other comorbid psychiatric disorders (ADHD only). In other words, ADHD patients with depression show distinct clinical characteristics compared to those without other psychiatric comorbidities. However, there are inconsistencies in the literature comparing the outcomes of patients with ADHD alone and those with co-existing depression, based on the sample size and measurement methods [8-12].

Since early detection and treatment have positive effects on the prognosis of ADHD [13], the referral routes have been considered clinically important. Children and adolescents with ADHD visit hospitals based on referral by their parents, teachers, or other caregivers. However, despite the clinical importance, there is no literature on the chief complaints and referral routes of patients with ADHD alone or those with depression.

The aim of this study was to compare the referral routes and chief complaints that could be the main reason for hospital visit, between patients with ADHD only and ADHD with comorbid depression. This study aimed to reveal the differences in clinical characteristics, including core symptoms that trigger the initial treatment of ADHD patients with and without depression.

\section{MATERIALS AND METHODS}

\section{Subjects}

This study was based on a retrospective chart review of the electronic medical records of all children and adolescents, aged 6 to 18 years, who visited the psychiatry department of five university hospitals in the metropolitan area (Kangbuk Samsung Hospital, Kyung Hee
University Hospital, Uijenogbu St. Mary's Hospital, Cha Medical Center, and Hallym University Sacred Heart Hospital) from January 2009 to December 2016. We aimed to identify patients with a clinical diagnosis of hyperkinetic disorder (F90) as ADHD from the collected data. Subjects with ADHD who were diagnosed with other psychiatric disorders, except depressive disorder (F32), were excluded. Data were collected with approval from the IRB of each hospital and the need for informed consent was waived including Hallym University Sacred Hospital (HALLYM 2020-02-012-001).

\section{Measurements}

\section{1) Chief complaints and demographic data}

The chief complaints of the subjects and their caregivers at the first visit to the hospital and the duration of each were collected. The complaints were classified into 29 categories as follows. : depression, anxiety, mood dysregulation, somatic symptoms, obsession, posttraumatic stress disorder (PTSD) symptoms, inattention, hyperactivity, impulsiveness and aggression, lying, oppositional and conduct-related problems, tic, suicidal ideas, self-mutilation and suicidal behavior, hallucinations and delusions, interpersonal problems, learning, sleep, and eating problems, substance abuse, problematic use of the internet and smartphone, sex-related issues (masturbation, prostitution, sexual behavior and victim of sexual abuse, and committing sexual abuse), school refusal, issues in child-parents relationship, domestic violence, child maltreatment (physical child abuse, psychological child abuse, and child neglect), victim of violence in school, and committing violence in school. In addition, demographic data including age, sex, and school grade were collected.

\section{2) Referral routes}

The referral routes were categorized into eight categories: caregiver's observation, patient's request, school advice, acquaintance advice, Wee center (a counselling facility operated by the education ministry) referral, referral by mental health welfare centers, private counselling facilities, and other medical institutions. All related referral route information was collected in cases of children who had visited multiple centers before visiting the medical research institute. 


\section{3) Clinical diagnosis}

Clinical diagnosis was made according to the International Statistical Classificstion 10th Revision (ICD-10) by child psychiatry specialists at each hospital. In addition, clinical diagnoses were re-established by tracking the patients' record within 8 weeks from the first visit in order to enhance the reliability of the original diagnosis. The first diagnosis was considered in cases where the 8-weeks follow-up was not possible.

\section{Data analysis and statistics}

Subjects were divided into two groups: ADHD with depression (ADHD-D) and ADHD only (ADHD-O), based on the presence of a depressive disorder (F32). An independent $\mathrm{t}$-test was performed for continuous variables to compare the difference between the two groups.

An independent variable was considered in cases of frequency variations between the chief complaints and referral routes. The $\chi^{2}$ test $(\mathrm{df}=1)$ and Fisher's exact test were used as appropriate to compare each of the eight referral routes and 29 chief complaints as a dependent variable. The $\chi^{2}$, odds ratio, and $\mathrm{p}$-values were calculated based on each chief complaint. All statistical analyses were conducted using IBM SPSS Statistics for Windows, Version 23.0 (IBM Co., Armonk, NY, USA).

\section{RESULTS}

\section{Sociodemographic characteristics}

First-visit clinical data of a total of 6,257 patients were reviewed. Among them, 1,948 patients (31.1\% of the total patients) were diagnosed with hyperkinetic disorder (F90). Among the patients with F90, 835 patients (42.9\%) were diagnosed with other comorbid disorders, including depressive disorder (F32). A total of 1,231 patients were selected as study subjects after excluding 715 patients diagnosed with coexisting psychiatric disorders other than F32.

Table 1 shows the demographic data of the patients with ADHD-O and ADHD-D. The proportion of male subjects in the ADHD-O group was significantly higher than in the ADHD-D group. Elementary school students were highest in number in the ADHD-O group, followed by middle and high school students. Similarly, the order of proportion was the same in the ADHD-D group; however, the ratio of middle and high school students increased. In other words, the proportion of elementary school students was substantially high in the ADHD-O but not in the ADHD-D group. The mean age of patients with ADHD-D was significantly higher of those with ADHD-O.

\section{Referral routes}

Table 2 shows a comparison of the referral routes between the two groups. Caregiver's observation was the most prevalent referral route in the ADHD-O group, fol-

Table 1. Sociodemographic characteristics of ADHD-O and ADHD-D

\begin{tabular}{lcccc}
\hline \multicolumn{1}{c}{ Variable } & ADHD-O $(n=1,111)$ & ADHD-D $(n=120)$ & $\chi^{2}$ & \\
\hline Sex & & & & \\
Male & $904(81.4)$ & $38(31.7)$ & 11.54 & 0.001 \\
Female & $207(18.6)$ & & & \\
School grade & & $54(45.0)$ & 46.49 & $<0.001$ \\
\hline Elementary school & $828(74.5)$ & $37(30.8)$ & 12.49 & $<0.001$ \\
\hline Middle school & $195(17.6)$ & $25(20.8)$ & 23.64 & $<0.001$ \\
\hline High school & $84(7.6)$ & $4(3.3)$ & 14.83 & $0.004^{\dagger}$ \\
\hline School drop-out & $4(0.4)$ & $12.27(3.11)$ & $<0.001$ \\
\hline Mean age & $9.79(3.10)$ & & \\
\hline
\end{tabular}

Values are presented as number (\%) or mean (standard deviation).

ADHD-0, attention-deficit/hyperactivity disorder only; ADHD-D, attention-deficit/hyperactivity disorder with depression.

${ }^{\dagger}$ Fisher's exact test. 
Table 2. Comparison of referral routes: ADHD-O versus ADHD-D

\begin{tabular}{lcccc}
\hline \multicolumn{1}{c}{ Variable } & ADHD-O (n=1,111) & ADHD-D (n=120) & $\chi^{2}$ & p-value \\
\hline Referral route & & & & \\
Caregiver's observation & $728(65.5)$ & $90(75.0)$ & 4.36 & 0.037 \\
\hline Patient's request & $27(2.4)$ & $9(7.5)$ & 9.80 & $0.006^{\dagger}$ \\
School advice & $382(34.4)$ & $27(22.5)$ & 6.89 & 0.009 \\
Acquaintance advice & $66(5.9)$ & $2(1.7)$ & 3.79 & 0.052 \\
Wee center & $7(0.6)$ & $1(0.8)$ & 0.07 & $0.561^{\dagger}$ \\
Mental health welfare center & $55(5.0)$ & $8(6.7)$ & 0.66 & 0.418 \\
Private counselling facility & $47(4.2)$ & $3(2.5)$ & 0.83 & $0.471^{\dagger}$ \\
\hline Other medical institution & $312(28.1)$ & $13(10.8)$ & 16.58 & $<0.001$ \\
Unidentified & $39(3.5)$ & $0(0.0)$ & 4.35 & 0.027 \\
\hline
\end{tabular}

Values are presented as number (\%).

ADHD-O, attention-deficit/hyperactivity disorder only; ADHD-D, attention-deficit/hyperactivity disorder with depression.

${ }^{\dagger}$ Fisher's exact test.

lowed by school referral, referral by other medical institutes, and acquaintance's advice. Similarly, caregiver's observation was ranked first in the ADHD-D group, followed by school referral, referral by other medical institutes, and patient's request. Caregiver's observations and patient's request were the significant referral routes in the ADHD-D group. The ADHD-O group had more cases of school advice and referral by other medical institutes than the ADHD-D group.

\section{Chief complaints}

Table 3 shows the difference in chief complaints between the two groups. Complaints of depression, mood dysregulation, suicidal ideas, self-mutilation, suicidal behavior, interpersonal problems, sexual problems, school refusal, and victims of school violence were significantly higher in the ADHD-D group. In contrast, inattention was the only complaint found to be higher in the ADHD-O group. The two groups did not demonstrate any meaningful differences in the prevalence of somatization, obsession, PTSD and acute stress reaction, hyperactivity, lying, oppositional and conduct-related problems, hallucination, delusion, learning, sleep and eating problems, substance abuse, problematic use of the internet and smartphone, issues in child-parent relationship, domestic child abuse, and school violence.

\section{DISCUSSION}

The present study was conducted using the medical records of Korean children and adolescents who visited university hospitals. The clinical characteristics including demographic characteristics, referral routes, and chief complaints of subjects with ADHD were investigated based on presence of the comorbid depression.

The higher proportion of female subjects in the ADHD-D group (18.6\% vs. $31.7 \%$ ) was consistent with the results of a previous meta-analysis, which showed that girls and young women with ADHD had more internalization problems such as depression and anxiety than boys and young men of the same age group [14]. In this study, patients in the ADHD-D group were older and were in higher school grades than those in the ADHDO group. Previous studies have reported that adolescents are more aware of their psychiatric problems [15] and that girls and young women avail psychiatric services more often [16]. Thus, the more active expression of symptoms of depression by older children and adolescents could have led to higher diagnosis of cases in this study. Conversely, younger children and adolescents have more difficulty in recognizing and expressing their inner problems. Therefore, younger patients with $\mathrm{AD}$ HD-O are likely to be diagnosed based on externalization and not internalizing problems such as depressive symptoms (as seen in older ADHD-D patients).

In the ADHD-D group, caregiver's observation and patient's request were ranked high as the referral route. The reason for higher patient requests in this group was 
Table 3. Comparison of chief complaints at first outpatient visit: ADHD-O versus ADHD-D

\begin{tabular}{|c|c|c|c|c|c|}
\hline Variable & $\begin{array}{l}\text { ADHD-O } \\
(n=1,111)\end{array}$ & $\begin{array}{c}\text { ADHD-D } \\
(n=120)\end{array}$ & $\chi^{2}$ & Odds ratio $(95 \% \mathrm{Cl})$ & $p$-value \\
\hline \multicolumn{6}{|l|}{ Chief complaints at first outpatient visit } \\
\hline Depression & $21(1.9)$ & $39(32.5)$ & 218.86 & $24.99(14.04-44.48)$ & $<0.001$ \\
\hline Anxiety & $42(3.8)$ & $11(9.2)$ & 7.63 & $2.57(1.29-5.13)$ & 0.006 \\
\hline Mood dysregulation & $111(10.0)$ & $19(15.8)$ & 3.91 & $1.70(1.00-2.87)$ & 0.048 \\
\hline Somatic symptoms & $30(2.7)$ & $5(4.2)$ & 0.84 & $1.57(0.60-4.12)$ & $0.359^{\dagger}$ \\
\hline Obsession & $3(0.3)$ & $2(1.7)$ & 5.22 & $6.26(1.04-37.84)$ & $0.077^{\dagger}$ \\
\hline PTSD symptoms/acute stress reaction & $3(0.3)$ & $1(0.8)$ & 1.06 & $3.10(0.32-30.07)$ & $0.337^{\dagger}$ \\
\hline Inattention & $786(70.7)$ & $66(55.0)$ & 12.60 & $0.51(0.35-0.74)$ & $<0.001$ \\
\hline Hyperactivity & $453(40.8)$ & $50(41.7)$ & 0.04 & $1.04(0.71-1.52)$ & 0.850 \\
\hline Impulsiveness, aggression & $245(22.1)$ & $28(23.3)$ & 0.10 & $1.08(0.69-1.68)$ & 0.748 \\
\hline Lying & $12(1.1)$ & $1(0.8)$ & 0.06 & $0.77(0.10-5.97)$ & $1.000^{\dagger}$ \\
\hline Oppositional problems & $25(2.3)$ & $6(5.0)$ & 3.34 & $2.29(0.92-5.69)$ & $0.113^{\dagger}$ \\
\hline Conduct problems & $22(2.0)$ & $4(3.3)$ & 0.96 & $1.70(0.58-5.04)$ & $0.310^{\dagger}$ \\
\hline Tic & $50(4.5)$ & $3(2.5)$ & 1.05 & $0.54(0.17-1.78)$ & 0.305 \\
\hline Suicidal ideas & $3(0.3)$ & $9(7.5)$ & 58.65 & $29.95(8.00-112.23)$ & $<0.001^{\dagger}$ \\
\hline Self-mutilation/suicidal behavior & $8(0.7)$ & $4(3.3)$ & 7.66 & $4.75(1.41-16.03)$ & $0.023^{\dagger}$ \\
\hline Auditory hallucination/delusion & $3(0.3)$ & $0(0.0)$ & 0.33 & $1.00(1.00-1.00)$ & $1.000^{\dagger}$ \\
\hline Interpersonal problems & $116(10.4)$ & $20(16.7)$ & 4.27 & $1.72(1.02-2.88)$ & 0.039 \\
\hline Learning problems & $120(10.8)$ & $18(15.0)$ & 1.92 & $1.46(0.85-2.50)$ & 0.166 \\
\hline Sleep problems & $14(1.3)$ & $2(1.7)$ & 0.14 & $1.33(0.30-5.92)$ & $0.664^{\dagger}$ \\
\hline Substance abuse & $3(0.3)$ & $0(0.0)$ & 0.33 & $1.00(1.00-1.00)$ & $1.000^{\dagger}$ \\
\hline Eating problems & $3(0.3)$ & $0(0.0)$ & 0.33 & $1.00(1.00-1.00)$ & $1.000^{\dagger}$ \\
\hline Problematic use of internet and smartphone & $29(2.6)$ & $5(4.2)$ & 0.98 & $1.62(0.62-4.72)$ & $0.370^{\dagger}$ \\
\hline Sex-related issues & $6(0.5)$ & $3(2.5)$ & 5.73 & $4.72(1.17-19.13)$ & $0.049^{\dagger}$ \\
\hline School refusal & $23(2.1)$ & $8(6.7)$ & 9.23 & $3.38(1.48-7.73)$ & $0.007^{\dagger}$ \\
\hline Child-parent relationship problems & $13(1.2)$ & $2(1.7)$ & 0.22 & $1.43(0.32-6.42)$ & $0.651^{\dagger}$ \\
\hline Domestic violence & $7(0.6)$ & $2(1.7)$ & 1.60 & $2.67(0.55-13.01)$ & $0.216^{\dagger}$ \\
\hline Child maltreatment & $2(0.2)$ & $1(0.8)$ & 1.90 & $4.66(0.42-51.77)$ & $0.265^{\dagger}$ \\
\hline Victim of violence in school & $11(1.0)$ & $4(3.3)$ & 4.94 & $3.45(1.08-11.00)$ & $0.050^{\dagger}$ \\
\hline Committing violence in school & $9(0.8)$ & $0(0.0)$ & 0.98 & $1.00(1.00-1.00)$ & $1.000^{\dagger}$ \\
\hline
\end{tabular}

Values are presented as number (\%).

ADHD-O, attention-deficit/hyperactivity disorder only; ADHD-D, attention-deficit/hyperactivity disorder with depression; $\mathrm{Cl}$, confidence interval; PTSD, post traumatic stress disorder.

${ }^{\dagger}$ Fisher's exact test.

assumed to be the higher proportion of female and older adolescents, who tend to directly avail mental health services $[15,16]$. The lower proportion of referral from the schools in the ADHD-D group could be explained by the fact that patients might visit the hospital directly rather than reporting their problems to the school. Furthermore, the symptoms of hyperactivity decrease as children and adolescents with ADHD grow older [17]. Moreover, there were fewer cases of externalization problems, which could have contributed to a reduction in the problems being revealed. Therefore, there were fewer cases of caregiver observation as the referral route in the ADHD-D group. In younger children, selfawareness of problems in not fully developed; therefore, caregivers tend to report their chief problems not from children. Our findings highlight the importance of diagnosing depression in ADHD patients through reports from custodians as well as by children themselves, in order to define depressive symptoms at the time of their first visit to the hospital.

Chief complaints of depression, anxiety, suicidal ideas and behaviors, and self-mutilation problems were higher 
in the ADHD-D group, which was consistent with previous research [18]. Rates of mood dysregulation were higher in the ADHD-D group. This could be attributed to hyperactivity of the amygdala, and hypoactivity of the ventral striatum, orbitofrontal cortex, and prefrontal cortex. These activities are involved in the emotional dysregulation in ADHD [19,20], which are related to decreasing functions of the prefrontal cortex as well in childhood depression [21]. ADHD and depression might intrude similar regions of the brain, which could have worsened emotional dysregulation in the ADHDD group. In addition, considering that children with ADHD and problems related to emotional control had more comorbid disorders and lower social functions [22], depression may have developed with age in children with mood dysregulation issues in the ADHD-D group in this study.

Depression could diminish concentration, which may be misinterpreted as inattention of ADHD, and might explain the higher rate of complaints of inattention in patients with ADHD-O in the present study. This means that inattention in patients with ADHD-D can be considered a secondary symptom of depression and might be excluded from the chief complaints. Given the observation that the patients with ADHD-D visited hospitals, there is a need to distinguish between inattention and diminished concentration caused by cognitive decline in depressive patients by engaging in intense interviews and self-reports to achieve more diagnostic accuracy in the future.

In this study, there were no statistically significant differences in hyperactivity, impulsiveness, and aggression, which was inconsistent with previous studies. Considering the improvement in the symptoms of impulsiveness and hyperactivity with age [22], there is a possibility that the difference between the two groups was not noticeable because the average age in the ADHDD group were higher. In addition, ADHD patients with anxiety have been reported to experience lesser degree of impulsiveness and hyperactivity [9]. Therefore, our findings that the patients in ADHD-D group presented more anxiety complaints, so it might decrease impulsive and aggressive behavior.

Interpersonal problems, school refusal, school violence, and sexual issues were more frequent in the ADHD-D group. Considering that there were more middle and high school students in ADHD-D group, the depressive ADHD adolescents in middle and high school might have raised more issues of the interpersonal relationship and school activity in this study. In addition, it may be inferred that ADHD adolescents with higher sensitivity to interpersonal relationships were burdened with more social stress than elementary students, thus presenting with more internal problems such as depression and school refusal. Therefore, appropriate intervention by the school and parents might be required to prevent depression in the ADHD patients.

In children and adolescents, depressive disorder is a well-known risk factor for impulse-control disorders such as conduct disorder [23]. However, in this study, there were no meaningful differences between the two groups in terms of conduct-related problems and oppositional behavior. This could be because patients with external impulsive behaviors such as conduct disorders were excluded from this study.

The limitations of this study are as follows. ADHD patients in this study showed a comorbidity rate of $42.9 \%$, which was less than the known general prevalence rate of $67 \%$ to $87 \%$ [24]. The subjects in this study visited tertiary medical institutes with severe symptoms of ADHD, and other comorbid disorders could have been ignored. In other words, the patients included in this study probably do not represent general ADHD patients, including those with ADHD in mild forms of condition. Clinical diagnoses were made based on the ICD-10 by mental health specialists rather than using structured diagnostic tools. This might have reduced the accuracy of diagnosis of ADHD and other comorbid disorders. In addition, we were unable to distinguish the subtypes of ADHD and depression in the study group. Several chief complaints such as interpersonal problems, school refusal, school violence, and sexual problems showed meaningful differences; however, the prevalence of each complaint in the two group was low. Finally, this crosssectional study, through assessment of first diagnostic records, did not provide a clear reason for depression in ADHD. Therefore, a longitudinal study would be needed in the future to understand the causes of complaints in patients with ADHD and the prognosis of children with ADHD and comorbid depression. Despite the results of our study were not corrected for multiple testing, our study was able to provide pilot information of comparing clinical characteristics between ADHD-O and ADHD-D. This large-scale multi-centered study of Korean children and adolescents with ADHD presented the different demographic characteristics, referral routes, 
and chief complaints based on comorbid depression, in a clinical setting. Our results suggested that identification of the symptoms of depression in ADHD was important, based on self-report of the patient. Further longitudinal studies using structured diagnostic tools are needed in the future to investigate the risk factors related to depression in children and adolescents with ADHD.

\section{CONFLICTS OF INTEREST}

The authors have nothing to disclose.

\section{ORCID}

\author{
Won-Seok Choi \\ https://orcid.org/0000-0003-1774-9504 \\ Hyun Ju Hong \\ https://orcid.org/0000-0002-6348-9996 \\ Myung Hun Jung \\ https://orcid.org/0000-0003-2393-3930 \\ Narei Hong \\ https://orcid.org/0000-0002-3781-9939 \\ Yong-Sil Kweon \\ https://orcid.org/0000-0001-5638-6350 \\ Geon Ho Bahn \\ https://orcid.org/0000-0002-3550-0422 \\ Ki-Hwan Yook \\ https://orcid.org/0000-0003-4053-2602 \\ Dong-Won Shin \\ https://orcid.org/0000-0001-6082-9599 \\ Duk-In Jon \\ https://orcid.org/0000-0002-1565-7940
}

\section{REFERENCES}

1. American Psychiatric Association. Diagnostic and statistical manual of mental disorders: DSM-5, fifth edition. Arlington: American Psychiatric Association; 2013.

2. Lee KS, Ryu YJ, Ahn DH, Shin YJ. A study of psychosocial variables within adhd with or without externalizing symptom. J Korean Acad Child Adolesc Psychiatr 1996;7:20312.

3. Ernst M, Zametkin AJ, Matochik JA, Jons PH, Cohen RM. DOPA decarboxylase activity in attention deficit hyperactivity disorder adults. A [fluorine-18]fluorodopa positron emission tomographic study. J Neurosci 1998;18:5901-7.
4. Pliszka SR. Comorbidity of attention-deficit/hyperactivity disorder with psychiatric disorder: an overview. J Clin Psychiatry 1998;59 Suppl 7:50-8.

5. Pliszka SR. Patterns of psychiatric comorbidity with attention-deficit/hyperactivity disorder. Child Adolesc Psychiatr Clin N Am 2000;9:525-40, vii.

6. Giedd JN. Bipolar disorder and attention-deficit/hyperactivity disorder in children and adolescents. J Clin Psychiatry 2000;61 Suppl 9:31-4.

7. Biederman J, Mick E, Faraone SV. Depression in attention deficit hyperactivity disorder (ADHD) children: "true" depression or demoralization? J Affect Disord 1998;47:11322.

8. Biederman J, Newcorn J, Sprich S. Comorbidity of attention deficit hyperactivity disorder with conduct, depressive, anxiety, and other disorders. Am J Psychiatry 1991;148:564-77.

9. Pliszka SR. Comorbidity of attention-deficit hyperactivity disorder and overanxious disorder. J Am Acad Child Adolesc Psychiatry 1992;31:197-203.

10. Biederman J, Faraone S, Mick E, Moore P, Lelon E. Child Behavior Checklist findings further support comorbidity between ADHD and major depression in a referred sample. J Am Acad Child Adolesc Psychiatry 1996;35:734-42.

11. Diler RS, Daviss WB, Lopez A, Axelson D, Iyengar S, Birmaher B. Differentiating major depressive disorder in youths with attention deficit hyperactivity disorder. J Affect Disord 2007;102:125-30.

12. Blackman GL, Ostrander R, Herman KC. Children with ADHD and depression: a multisource, multimethod assessment of clinical, social, and academic functioning. J Atten Disord 2005;8:195-207.

13. Biederman J, Petty CR, Woodworth KY, Lomedico A, Hyder LL, Faraone SV. Adult outcome of attention-deficit/hyperactivity disorder: a controlled 16-year follow-up study. J Clin Psychiatry 2012;73:941-50.

14. Gershon J. A meta-analytic review of gender differences in ADHD. J Atten Disord 2002;5:143-54.

15. Zwaanswijk M, Van der Ende J, Verhaak PF, Bensing JM, Verhulst FC. Factors associated with adolescent mental health service need and utilization. J Am Acad Child Adolesc Psychiatry 2003;42:692-700.

16. Burns BJ, Phillips SD, Wagner HR, Barth RP, Kolko DJ, Campbell Y, et al. Mental health need and access to mental health services by youths involved with child welfare: a national survey. J Am Acad Child Adolesc Psychiatry 2004; 43:960-70.

17. Hales RE, Yudofsky SC, Roberts LW. The American Psychiatric Publishing textbook of psychiatry. 6th ed. Washington DC: American Psychiatric Publishing; 2014.

18. Biederman J, Ball SW, Monuteaux MC, Mick E, Spencer TJ, McCreary M, et al. New insights into the comorbidity between ADHD and major depression in adolescent and young adult females. J Am Acad Child Adolesc Psychiatry 2008;47:426-34. 
19. Shaw P, Stringaris A, Nigg J, Leibenluft E. Emotion dysregulation in attention deficit hyperactivity disorder. Am J Psychiatry 2014;171:276-93.

20. Tomasi D, Volkow ND. Abnormal functional connectivity in children with attention-deficit/hyperactivity disorder. Biol Psychiatry 2012;71:443-50.

21. Rubia K, Overmeyer S, Taylor E, Brammer M, Williams SC, Simmons A, et al. Hypofrontality in attention deficit hyperactivity disorder during higher-order motor control: a study with functional MRI. Am J Psychiatry 1999;156:891-
6.

22. Wilens TE, Biederman J, Spencer TJ. Attention deficit/ hyperactivity disorder across the lifespan. Annu Rev Med 2002;53:113-31.

23. Cook MN, Peterson J, Sheldon C. Adolescent depression: an update and guide to clinical decision making. Psychiatry (Edgmont) 2009;6:17-31.

24. Barkley RA. Attention-deficit hyperactivity disorder: a handbook for diagnosis and treatment. 4th ed. New York: Guilford Press; 2015. 